\title{
Role of Stromal Myofibroblasts in the Progression of Oral Lesions from Dysplasia to Invasive Carcinoma
}

\begin{abstract}
Background: Concurrent with the conversion of nondiseased epithelial tissue to precancerous epithelium and finally to carcinoma, the stroma also changes from normal-to-primed to tumor-associated reactive stroma. Cancerous cells secrete cytokines that promote differentiation of fibroblasts into cancer-associated fibroblasts/myofibroblasts. Myofibroblasts are tumor promoting and correlate with poor survival in many cancers. Vimentin expression is noted in epithelial cells of histologically more malignant oral squamous cell carcinoma (OSCC). Aim and Objectives: The aim of this study is to understand the role of tumor microenvironment by analyzing the expression of $\alpha$-smooth muscle actin ( $\alpha$-SMA) in stromal myofibroblasts and to find a possible association between intensity and pattern of myofibroblast expression and progression of oral lesions from mild, moderate, and severe dysplasia to verrucous and invasive carcinomas. Materials and Methods: The study was divided into two groups. Sixty cases of premalignant lesions and 60 cases of OSCC were taken as the study groups. Smooth muscle cells surrounding the blood vessels were taken as positive control (internal control). Immunohistochemistry (IHC) for $\alpha$-SMA was performed for the identification of myofibroblasts. The cases were then assessed for intensity and pattern of myofibroblastic proliferation. IHC for vimentin-positive epithelial cells was also done. Results: Fisher's exact test and Chi-square test were used. There was an increased $\alpha$-SMA expression in malignant cases. Few cases of dysplasia showed focal staining pattern, whereas network pattern predominated in invasive carcinomas. Vimentin expression was seen in histologically more malignant OSCC cases and higher number of myofibroblasts was observed in such cases. Conclusion: Myofibroblasts increase as the disease progresses. Network arrangement of myofibroblasts represents higher invasive characteristics and a weaker prognosis.
\end{abstract}

Keywords: Alpha-smooth muscle actin, cancer-associated fibroblasts, dysplasia, myofibroblast, oral squamous cell carcinoma

\section{Introduction}

Oral squamous cell carcinoma (OSCC) is the eighth most prevalent malignant neoplasm worldwide, with an overall survival rate of $<50 \% .{ }^{[1]}$ Invasive carcinoma is often preceded by clinically identifiable, potentially malignant lesions and conditions such as leukoplakia, erythroplakia, and oral submucous fibrosis. ${ }^{[2]}$

Transformation of normal oral mucosa to squamous dysplasia and ultimately to SCC represents a complicated process involving numerous etiologic factors. ${ }^{[3]}$ Approximately $10 \%-20 \%$ of oral dysplasias develop carcinomatous features and they eventually invade beyond the basement membrane. ${ }^{[4]}$ The mechanisms involved in this progression are not well-understood. ${ }^{[2,5]}$

This is an open access journal, and articles are distributed under the terms of the Creative Commons Attribution-NonCommercial-ShareAlike 4.0 License, which allows others to remix, tweak, and build upon the work non-commercially, as long as appropriate credit is given and the new creations are licensed under the identical terms.

For reprints contact: reprints@medknow.com
Concurrent with the conversion of nondiseased epithelial tissue to precancerous epithelium and finally to carcinoma, the stroma also changes from normal-to-primed to tumor-associated reactive stroma. ${ }^{[6]}$ The tumor microenvironment plays an important role in tumor initiation, proliferation, differentiation, migration, and metastasis. ${ }^{[7]}$ Cancerous cells secrete cytokines such as transforming growth factor beta-1 (TGF $\beta-1$ ) that promotes differentiation of fibroblasts into cancer-associated fibroblasts $(\mathrm{CAF}) /$ myofibroblasts. ${ }^{[8]}$

Myofibroblasts are defined immunohistochemically by the presence of $\alpha$-smooth muscle actin ( $\alpha$-SMA), vimentin, smooth muscle-myosin heavy chain, desmin, calponin, and $\alpha 1$-integrin. ${ }^{[9]}$ These cells have contractile properties and are involved in inflammation, wound healing, fibrosis, and oncogenesis. They produce inflammatory

How to cite this article: Khalid A, Siddiqui S, Faizi N,
Hassan J, Nehal N, Siddiqui A. Role of stromal
myofibroblasts in the progression of oral lesions
from dysplasia to invasive carcinoma. Indian J Med
Paediatr Oncol 2019;40:536-41.

\author{
Aeman Khalid', \\ Safia Siddiqui ${ }^{2}$, \\ Nafis Faizi ${ }^{3}$, \\ Jowairiah Hassan ${ }^{1}$, \\ Naila Nehal ${ }^{4}$, \\ Atiuddin Siddiqui ${ }^{4}$
}

${ }^{1}$ Department of Pathology, Jawahar Lal Nehru Medical College, ${ }^{3}$ Department of Community Medicine, Jawahar Lal Nehru Medical College, AMU, Aligarh, ${ }^{2}$ Department of Oral Pathology and Microbiology, Sardar Patel Postgraduate Institute of Dental and Medical Sciences, ${ }^{4}$ Department of Periodontology, Career Postgraduate Institute of Dental Sciences and Hospital, Lucknow, Uttar Pradesh, India

Submitted: 21-May-2018

Revised: 13-Sep-2018

Accepted: 29-Nov-2018

Published: 17-Feb-2020

Address for correspondence:

Dr. Safia Siddiqui,

Department of Oral Pathology and Microbiology, Sardar Patel Postgraduate Institute of Dental and Medical Sciences, Lucknow - 226025 , Uttar Pradesh, India.

E-mail: safiasidd4@gmail.com

Access this article online

Website: www.ijmpo.org

DOI: 10.4103/ijmpo.ijmpo_121_18 Quick Response Code:

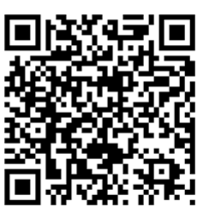


mediators and growth factors which help in extracellular matrix reorganization and epithelial cell proliferation. ${ }^{[4]}$ The expression of myofibroblasts has been demonstrated in numerous aggressive and malignant lesions. ${ }^{[10-13]}$

The aim of this study is to understand the role of tumor microenvironment by analyzing the expression of $\alpha$-SMA in stromal myofibroblasts and to find a possible association between intensity and pattern of myofibroblast expression and progression of oral lesions from mild, moderate, and severe dysplasia to verrucous and invasive carcinomas.

\section{Materials and Methods}

After obtaining permission from the Institutional Ethical Committee, the present study was carried out on premalignant and Malignant tissues of the oral cavity, obtained from the archives of the department archived in the department. Medical records including pathology reports were reviewed to record the patient's age, sex, tumor location, tumor size, differentiation, invasion depth of tumor, lymph node metastasis, and clinical stage. Patients receiving preoperative chemotherapy and radiotherapy were excluded from the study.

The study was divided into two groups:

- Group 1 (Study Group 1): Comprised of premalignant cases which were further categorized into mild, moderate, and severe dysplasia based on histopathology as shown in Table 1. From each category, 20 cases were chosen for observing the expression of $\alpha$-SMA

- Group 2 (Study Group 2): Comprised of malignant cases. Out of the 60 malignant cases, 15 cases of verrucous carcinoma (VC), 15 cases of well-differentiated SCC (WDSCC), 15 cases of moderately differentiated SCC (MDSCC), and 15 cases of poorly differentiated SCC (PDSCC) were chosen

- Smooth muscle cells surrounding the blood vessels were taken as a positive control (internal control).

Sections of $5-\mu$ thick were obtained from the paraffin block and stained with hematoxylin and eosin. Degree of dysplasia of premalignant and degree of differentiation of the malignant lesions were noted.

For immunohistochemistry (IHC), 3-4- $\mu$ thick sections were obtained from the paraffin block on poly-l-lysine coated slides. These sections were deparaffinized and hydrated. Antigen retrieval was done by immersing the slides in prewarmed citrate buffer $(\mathrm{pH}-6.0)$ and heating

\begin{tabular}{lcccc}
\hline \multicolumn{4}{c}{ Table 1: Distribution of premalignant lesions } \\
\hline & $\begin{array}{c}\text { Number of } \\
\text { cases (\%) }\end{array}$ & $\begin{array}{c}\text { Mild } \\
\text { dysplasia }\end{array}$ & $\begin{array}{c}\text { Moderate } \\
\text { dysplasia }\end{array}$ & $\begin{array}{c}\text { Severe } \\
\text { dysplasia }\end{array}$ \\
\hline Leukoplakia & $54(68)$ & 14 & 26 & 14 \\
Erythroplakia & $15(19)$ & 03 & 04 & 08 \\
Lichen planus & $6(8)$ & 06 & 00 & 00 \\
OSMF & $4(5)$ & 04 & 00 & 00 \\
Total (\%) & $79(100)$ & $27(34)$ & $30(38)$ & $22(28)$ \\
\hline
\end{tabular}

OSMF - Oral submucous fibrosis in a microwave oven at $95^{\circ} \mathrm{C}-98^{\circ} \mathrm{C}$ for 20 min. Blocking of endogenous peroxidase was done by dipping slides (kept in moist chamber) in a mixture of $50 \mathrm{ml}$ methanol with $1.5 \mathrm{ml}$ hydrogen peroxide for $30 \mathrm{~min}$, followed by washing in distilled water for $5 \mathrm{~min}$. Slides were cooled to room temperature and washed in Tris buffer ( $\mathrm{pH}-7.2)$. Primary ready to use antibody (Thermo Scientific monoclonal mouse anti-human $\alpha$-SMA antibody; clone: IA4) in dilution of 1:50-100 was added to the sections and slides were incubated for $30 \mathrm{~min}$ at room temperature. Slides were then washed in Tris buffer $(\mathrm{pH}-7.2)$ and secondary antibody (horseradish Peroxidase) was added to the sections and incubated for $30 \mathrm{~min}$. The slides were further washed in Tris buffer $(\mathrm{pH}-7.2)$, followed by the addition of diaminobenzidine (DAB) chromogen in DAB buffer (in the ratio of 1:50). The slides were incubated for $3 \mathrm{~min}$ and counterstained with hematoxylin. Similarly, tissue sections of $3 \mu \mathrm{m}$ were used for IHC analysis of vimentin in the epithelial cells of OSCC. This was carried out with the avidin-biotin complex method, using monoclonal antibody antivimentin (Dakopatts, Denmark) 1:200, and peroxidase-antiperoxidase method, overnight at $4^{\circ} \mathrm{C}$. 3-3'-DAB tetrahydrochloride was used as chromogen.

Vimentin and $\alpha$-SMA cells labeled by the antibody were identified by strong dark brown cytoplasmic staining of epithelial cells and myofibroblasts, respectively. $\alpha$-SMA cases were then assessed for intensity and pattern of myofibroblastic proliferation.

Assessment of intensity and pattern of $\alpha$-smooth muscle actin expression

Intensity score for $\alpha$-smooth muscle actin ${ }^{[14]}$

The percentage of cells positive for $\alpha$-SMA in the tumor stroma was recorded as:

- Absent $/ 0=$ no positive cells

- Mild $/ 1+=1 \%-33 \%$ positive cells

- Moderate $/ 2+=34 \%-66 \%$ positive cells

- Intense $/ 3+=67 \%-100 \%$ positive cells.

Pattern of $\alpha$-smooth muscle actin expression ${ }^{[15]}$

The distribution and arrangement of positive-stained myofibroblast cells were classified into three groups:

- Focal or no special arrangement

- Network: Myofibroblasts with vesicular nuclei and abundant cytoplasm arranged in multiple rows with interwoven network of cytoplasmic extensions forming a network in the stroma of the connective tissue

- Spindle: Myofibroblasts arranged in one to three rows in a regular order in the periphery of the neoplastic islands or in the connective tissues with distinctive cell margins around myofibroblasts and malignant tissue.

\section{Results}

The statistical analysis was done using Fisher's exact test and Chi-square test to evaluate the significance 
of difference between the association of variables. $P \leq 0.05$ was considered to be statistically significant. For deduction of any association between specific group or grade, the data were clubbed. During clubbing, the data were added together to form groups to facilitate comparisons.

Majority of the premalignant cases $(62 \%)$ were seen in the fourth and fifth decades of life with a mean age of $46.6 \pm 7.46$ years, while most of the malignant cases $(75 \%)$ were seen in the fifth and sixth decades with a mean age of $53.93 \pm 8.51$ years Majority of cases in both the groups were males and floor of the mouth was the most common site involved.

The expression of $\alpha$-SMA in premalignant lesions according to the degrees of dysplasia is shown in Table 2. Stroma of most of the dysplasia cases was negative for $\alpha$-SMA except for the blood vessels as shown in Figure 1. Only seven cases of dysplasia out of 60 were positive for $\alpha$-SMA. Out of these seven cases, two were of moderate dysplasia which showed mild staining and five were of severe dysplasia. Three cases out of these five showed mild staining, whereas the remaining two cases showed an intensity score of +2 . There was a statistically significant difference in the $\alpha$-SMA expression among dysplasia $(P=0.046)$. Pattern of $\alpha$-SMA expression in premalignant lesions is shown in Table 3.

Table 2: Expression of $\alpha$-smooth muscle actin in premalignant lesions

\begin{tabular}{lccc}
\hline Type of lesion & $\begin{array}{c}\text { Number } \\
\text { of cases }\end{array}$ & \multicolumn{2}{c}{$\boldsymbol{\alpha}$-SMA intensity score (\%) } \\
\cline { 3 - 4 } & 20 & Negative & Positive \\
\hline Mild dysplasia & $20(100)$ & 0 \\
Moderate dysplasia & 20 & $18(90)$ & $2(10)$ \\
Severe dysplasia & 20 & $15(75)$ & $5(15)$ \\
$\chi^{2}$, df, $P$ & & $6.15,2,0.046$ & \\
\hline
\end{tabular}

$\alpha$-SMA $-\alpha$-smooth muscle actin

Table 3: Pattern of expression of $\alpha$-smooth muscle actin in premalignant lesions

\begin{tabular}{lccccc}
\hline Type of lesion & $\begin{array}{c}\text { Number Negative } \\
\text { of cases }\end{array}$ & $\begin{array}{c}\text { Focal } \\
\text { staining }\end{array}$ & $\begin{array}{c}\text { Network Spindle } \\
\text { pattern }\end{array}$ & pattern & pattern \\
\hline Mild dysplasia & 20 & 20 & 0 & 0 & 0 \\
Moderate dysplasia & 20 & 18 & 2 & 0 & 0 \\
Severe dysplasia & 20 & 15 & 5 & 0 & 0 \\
\hline
\end{tabular}

Fisher's exact probability test, $P=0.05$
The expression of $\alpha$-SMA in malignant lesions is shown in Table 4 and Figures 2-5. When data were compared statistically, a significant increase in $\alpha$-SMA intensity score was observed in invasive carcinomas in comparison to $\mathrm{VC}$. Among the different degrees of differentiation of invasive SCC, a statistically significant increase of $\alpha$-SMA expression was found in MDSCC as compared to WDSCC and in PDSCC as compared to $\operatorname{MDSCC}(P<0.001)$.

Vimentin expression was noted in 45\% (27) cases and was found to be positive in epithelial cells of histologically more malignant OSCC as shown in Figure 6. Such cases showed intense $\alpha$-SMA expression. None of the VC cases showed vimentin positivity. All the 15 cases of poorly differentiated while 12 cases of moderately OSCC were vimentin positive.

A variation in the pattern of $\alpha$-SMA expression was noted among the malignant lesions, ranging from focal to network to spindle patterns of stromal myofibroblast positivity for $\alpha$-SMA as shown in Table 5. Statistically significant difference was found in the pattern of $\alpha$-SMA expression among the malignant lesions $(P<0.001)$. On comparing spindle and network patterns of expression, significantly more cases showed network pattern of $\alpha$-SMA in more dedifferentiated carcinoma.

On comparing premalignant and malignant cases, out of 60 , only seven premalignant cases showed $\alpha$-SMA positivity,

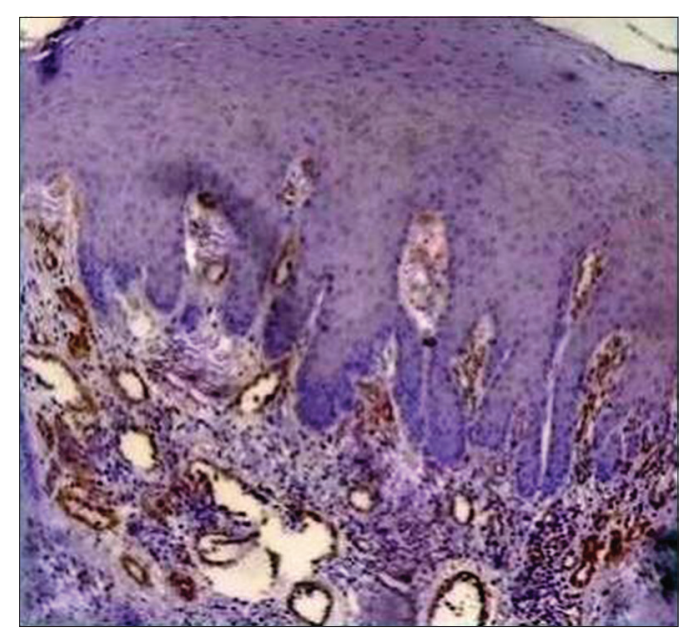

Figure 1: Histopathological image of mild dysplasia showing $\alpha$-smooth muscle actin positivity only in the blood vessels, rest of the stroma is negative for $\alpha$-smooth muscle actin $(\times 400)$

\begin{tabular}{|c|c|c|c|c|c|}
\hline \multirow[t]{2}{*}{ Type of lesion } & \multirow{2}{*}{$\begin{array}{l}\text { Number } \\
\text { of cases }\end{array}$} & \multicolumn{4}{|c|}{$\alpha$-SMA intensity score (\%) } \\
\hline & & $\mathbf{0}$ & $1+($ mild $)$ & $2+($ moderate $)$ & $3+$ (intense) \\
\hline Verrucous carcinoma & 15 & $3(20)$ & $10(67)$ & $2(13)$ & 0 \\
\hline Well-differentiated SCC & 15 & $2(13)$ & $9(60)$ & $4(27)$ & 0 \\
\hline Moderately differentiated SCC & 15 & 0 & $4(27)$ & $8(53)$ & $3(20)$ \\
\hline Poorly differentiated SCC & 15 & 0 & 0 & $4(27)$ & $11(73)$ \\
\hline
\end{tabular}

Fisher's exact test $P<0.001$. SCC - Squamous cell carcinoma; $\alpha$-SMA $-\alpha$-smooth muscle actin 


\begin{tabular}{lccccc}
\hline \multicolumn{5}{c}{ Table 5: Pattern of expression of $\boldsymbol{\alpha}$-smooth } \\
\hline Type of lesion & \multicolumn{1}{c}{ Number actin in malignant lesions } \\
\hline Verrucous carcinoma & 15 & $3(21)$ & $11(73)$ & $1(6)$ & 0 \\
Well-differentiated SCC & 15 & $2(13)$ & $10(67)$ & 0 & $3(20)$ \\
Moderately differentiated SCC & 15 & 0 & $2(13)$ & $8(53)$ & $5(33)$ \\
Poorly differentiated SCC & 15 & 0 & 0 & $12(80)$ & $3(20)$ \\
\hline
\end{tabular}

Fisher's exact test $P<0.001$. SCC - Squamous cell carcinoma



Figure 2: Histopathological image of verrucous carcinoma showing mild $\alpha$-smooth muscle actin positivity in the stroma, myofibroblasts can be seen distributed in focal pattern $(\times 400)$

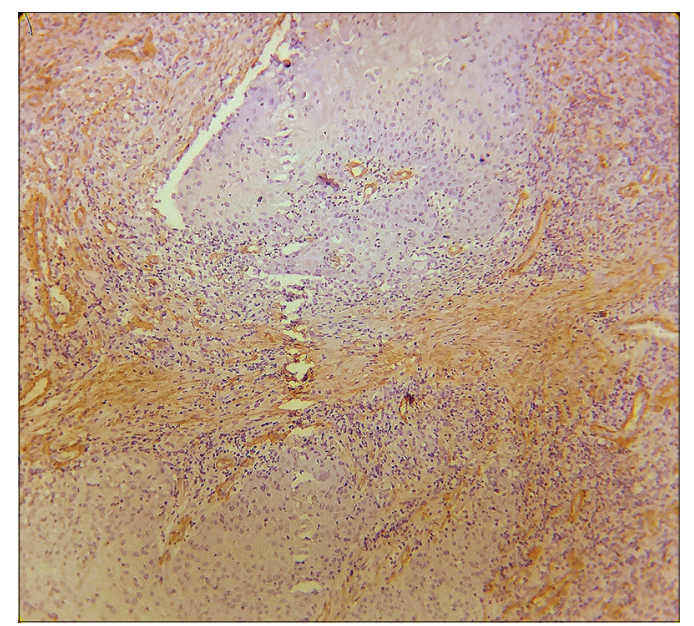

Figure 4: Histopathological image of moderately differentiated squamous cell carcinoma showing intense $\alpha$-smooth muscle actin positivity in the stroma, myofibroblasts can be seen distributed in spindle pattern $(\times 400)$

while 55 malignancy cases out of 60 were positive for $\alpha$-SMA. It is clearly evident from our study that there is an increased $\alpha$-SMA expression in malignant cases in comparison to premalignant cases (Chi-square $=76.9$, $\mathrm{df}=1, P<0.001)$.

\section{Discussion}

In our study, the premalignant lesions were found to be more common in the fourth and fifth decades of life. Similar findings were published in another study where leukoplakia was found

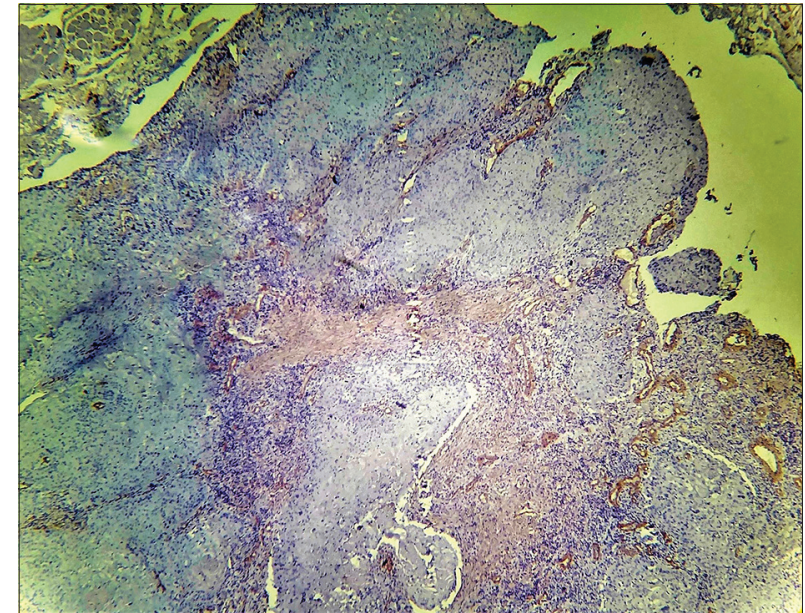

Figure 3: Histopathological image of well-differentiated squamous cell carcinoma showing mild $\alpha$-smooth muscle actin positivity in the stroma, myofibroblasts can be seen distributed in focal pattern $(\times 400)$

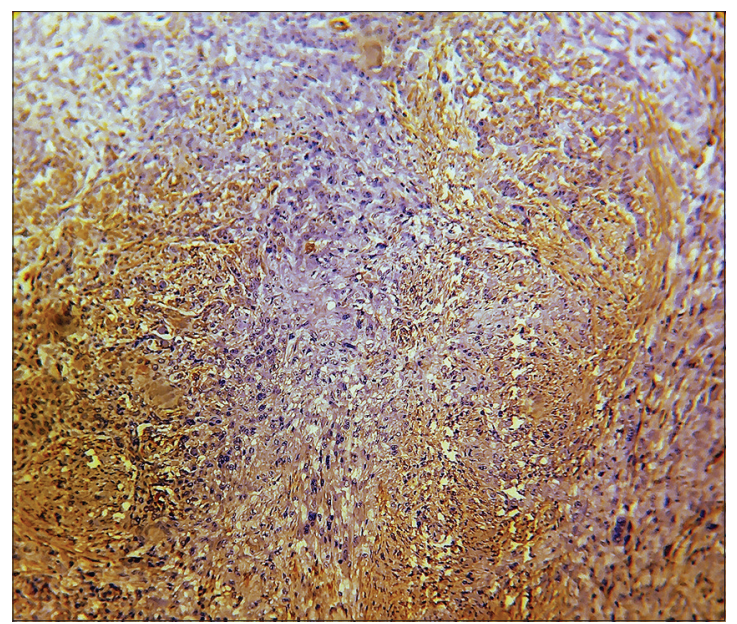

Figure 5: Histopathological image of poorly differentiated squamous cell carcinoma showing intense $\alpha$-smooth muscle actin positivity in the stroma, myofibroblasts can be seen distributed in network pattern $(\times 400)$

to be most frequent in the middle age. ${ }^{[16]}$ The malignant lesions were more common in the fifth and sixth decades of life. This was in accordance with another study, where oral cancer was found to be most common in middle- and older-aged individuals. ${ }^{[17,18]}$

In our study, the premalignant and malignant lesions were more common in males as compared to females which can be attributed to increased exposure of risk factors, such as smoking, tobacco, and betel chewing in males. Similar findings were seen in other studies also. ${ }^{[1,19]}$ 


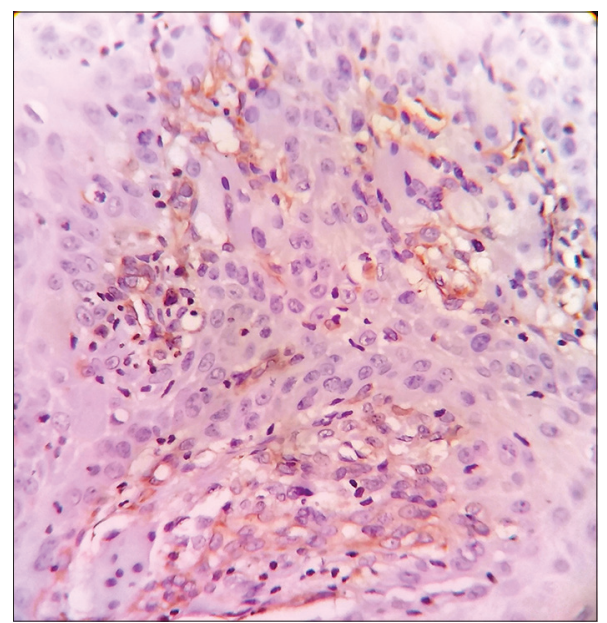

Figure 6: Histopathological image of poorly differentiated squamous cell carcinoma showing vimentin positivity in the epithelial cells of oral squamous cell carcinoma $(\times 400)$

The most common sites for oral cavity lesions were found to be floor of the mouth. This could be attributed to the increased exposure of the floor of the mouth to tobacco and betel quid as per the habitual placement of these substances at this site.

Regarding the presence of myofibroblasts, $\alpha$-SMA expression is not observed in the stroma of normal oral mucosa, except for the blood vessels. ${ }^{[20,21]}$ Among dysplasia, $\alpha$-SMA expression was absent in mild epithelial dysplasia, only $10 \%$ cases of moderate epithelial dysplasia showed mild $\alpha$-SMA expression; however, mild-to-moderate expression was seen $25 \%$ cases of severe dysplasia.

Similar to our study, no myofibroblasts was seen in low-risk dysplasia cases and only $46.66 \%$ of high-risk dysplasia cases (moderate and severe dysplasia) were positive for $\alpha$-SMA in another study. ${ }^{[20]}$ In a similar study, $\alpha$-SMA-positive myofibroblasts were seen in only $22 \%$ of epithelial dysplasia cases. ${ }^{[22]}$ Our results were not consistent with the findings of another study where they found no myofibroblasts in dysplasia. ${ }^{[21]}$

We found that few cases of epithelial dysplasia which were positive for $\alpha$-SMA showed mild staining. In case of $\mathrm{VC}$ and WDSCC, most of the cases that were positive also showed mild staining, whereas in case of MDSCC, the majority of cases showed moderate staining, while most of the cases of PDSCC were intensely positive for $\alpha$-SMA. It was clearly evident from our study that there is an increased $\alpha$-SMA expression in malignant cases in comparison to premalignant cases. An increased $\alpha$-SMA expression was seen in $\mathrm{VC}$ as compared to dysplasia and an increased expression in invasive carcinomas in comparison to VC. Among the invasive carcinomas, an increased expression was noted in MDSCC as compared to WDSCC and in PDSCC as compared to MDSCC. Our findings were in accordance with other similar studies. ${ }^{[20,23]}$

In a retrospective study on 282 OSCC patients, it was found that the strongest independent risk factor of early OSCC death was a feature of stroma and not the tumor cells. SMA was strongly associated with OSCC mortality regardless of whether patients had advanced disease or not. ${ }^{[24]}$

Regarding arrangement of myofibroblasts, we found focal arrangement of myofibroblasts in few cases of epithelial dysplasia that were positive, whereas in VC and WDSCC, most of the positive cases showed focal pattern of expression. Majority of the MDSCC and PDSCC cases showed a network pattern of expression in our study. These findings were in accordance to the observations seen in other studies. ${ }^{[15,20,22,25]}$

Regarding the origin of myofibroblasts multiple theories have been proposed. Its formation can be attributed to epithelialmesenchymal transformation, mesenchymal-mesenchymal transformation, or from endothelial-mesenchymal transformation. ${ }^{[7]}$ In studies on highly polymorphic ductal carcinoma, in situ of breast and noninvasive urothelial carcinoma of bladder, respectively, it was demonstrated that factors derived from aggressive tumor cells are able to diffuse through the basement membrane and stimulate myofibroblast transformation. ${ }^{[25,26]}$ OSCC-derived TGF- $\beta 1$ promotes fibroblast-myofibroblast transdifferentiation and factors released from these myofibroblasts, inturn induces tumor cellular proliferation. ${ }^{[22-24]}$

Regarding the role of myofibroblasts in carcinomas, it has been seen that an increase in the number of $\alpha$-SMA-positive myofibroblasts and change in distribution pattern during oral carcinogenesis process is related to tumor invasion. ${ }^{[22-24]}$ Stromal myofibroblasts release matrix metalloproteinase (MMP) to remodel the stroma so as to facilitate invasion. ${ }^{[22]}$ Hyaluronan synthase 2 is one of the key regulators responsible for CAF-mediated OSCC progression and acts by modulating the balance of MMP1 and tissue inhibitor of metalloproteinases 1. ${ }^{[27]}$

Network arrangement of myofibroblasts in SCC represents higher invasive characteristics and weaker prognosis. It can be said that because of the higher number of myofibroblasts in network arrangements neoplastic lesions, show more severe invasive behavior in comparison to spindle arrangement. ${ }^{[15,22]}$

Myofibroblasts are tumor promoting and correlate with poor survival in many cancers, which has led to their emergence as potential therapeutic targets. ${ }^{[28,29]}$ Pharmacological inhibition of NOX4 may have broad applicability for stromal targeting across cancer types. ${ }^{[30]}$

\section{Conclusion}

The presence of myofibroblasts, as measured by $\alpha$-SMA expression, increases as the disease progresses from premalignancy to $\mathrm{VC}$ and to invasive OSCC. Transdifferentiation of myofibroblasts is induced somewhere in the preinvasive or early-invasive stage of OSCC, and further loss of tumoral differentiation (increasing grade) affects the number of these cells. These cells facilitate 
local and distant invasion of tumor. Therefore, the study of myofibroblasts in the stroma has become an important area of research and a potential target for therapeutic intervention.

The presence, distribution, and arrangement of myofibroblasts in the stroma can be considered as an assessment tool for categorizing oral premalignant and malignant lesions and can also be used as a prognostic marker.

\section{Financial support and sponsorship}

Nil.

\section{Conflicts of interest}

There are no conflicts of interest.

\section{References}

1. Warnakulasuriya S. Living with oral cancer: Epidemiology with particular reference to prevalence and life-style changes that influence survival. Oral Oncol 2010;46:407-10.

2. Napier SS, Speight PM. Natural history of potentially malignant oral lesions and conditions: An overview of the literature. J Oral Pathol Med 2008;37:1-0.

3. De Wever O, Mareel M. Role of tissue stroma in cancer cell invasion. J Pathol 2003;200:429-47.

4. Powell DW, Mifflin RC, Valentich JD, Crowe SE, Saada JI, West AB, et al. Myofibroblasts. I. Paracrine cells important in health and disease. Am J Physiol 1999;277:C1-9.

5. Hsue SS, Wang WC, Chen CH, Lin CC, Chen YK, Lin LM, et al. Malignant transformation in 1458 patients with potentially malignant oral mucosal disorders: A follow-up study based in a Taiwanese hospital. J Oral Pathol Med 2007;36:25-9.

6. Amatangelo MD, Bassi DE, Klein-Szanto AJ, Cukierman E. Stroma-derived three-dimensional matrices are necessary and sufficient to promote desmoplastic differentiation of normal fibroblasts. Am J Pathol 2005; 167:475-88.

7. Kojima Y, Acar A, Eaton EN, Mellody KT, Scheel C, Ben-Porath I, et al. Autocrine TGF-beta and stromal cell-derived factor-1 (SDF-1) signaling drives the evolution of tumor-promoting mammary stromal myofibroblasts. Proc Natl Acad Sci U S A 2010;107:20009-14.

8. Liotta LA, Kohn EC. The microenvironment of the tumour-host interface. Nature 2001;411:375-9.

9. Nakayama H, Enzan H, Miyazaki E, Naruse K, Kiyoku H, Hiroi M, et al. The role of myofibroblasts at the tumor border of invasive colorectal adenocarcinomas. Jpn J Clin Oncol 1998;28:615-20.

10. Desmoulière A, Guyot C, Gabbiani G. The stroma reaction myofibroblast: A key player in the control of tumor cell behavior. Int J Dev Biol 2004;48:509-17.

11. Zidar N, Gale N, Kambic V, Fischinger J. Proliferation of myofibroblasts in the stroma of epithelial hyperplastic lesions and squamous carcinoma of the larynx. Oncology 2002;62:381-5.

12. Adegboyega PA, Mifflin RC, DiMari JF, Saada JI, Powell DW. Immunohistochemical study of myofibroblasts in normal colonic mucosa, hyperplastic polyps, and adenomatous colorectal polyps. Arch Pathol Lab Med 2002;126:829-36.

13. Surowiak P, Suchocki S, Györffy B, Gansukh T, Wojnar A, Maciejczyk A, et al. Stromal myofibroblasts in breast cancer: Relations between their occurrence, tumor grade and expression of some tumour markers. Folia Histochem Cytobiol
2006;44:111-6.

14. Tuxhorn JA, Ayala GE, Rowley DR. Reactive stroma in prostate cancer progression. J Urol 2001;166:2472-83.

15. Vered M, Allon I, Buchner A, Dayan D. Stromal myofibroblasts accompany modifications in the epithelial phenotype of tongue dysplastic and malignant lesions. Cancer Microenviron 2009;2:49-57.

16. Neville BW, Day TA. Oral cancer and precancerous lesions. CA Cancer J Clin 2002;52:195-215.

17. Schantz SP, Yu GP. Head and neck cancer incidence trends in young Americans, 1973-1997, with a special analysis for tongue cancer. Arch Otolaryngol Head Neck Surg 2002;128:268-74.

18. Llewellyn CD, Johnson NW, Warnakulasuriya KA. Risk factors for squamous cell carcinoma of the oral cavity in young people - A comprehensive literature review. Oral Oncol 2001;37:401-18.

19. Silverman S Jr., Gorsky M, Lozada F. Oral leukoplakia and malignant transformation. A follow-up study of 257 patients. Cancer 1984;53:563-8.

20. Chaudhary M, Gadbail AR, Vidhale G, Mankar Gadbail MP, Gondivkar SM, Gawande M, et al. Comparison of myofibroblasts expression in oral squamous cell carcinoma, verrucous carcinoma, high risk epithelial dysplasia, low risk epithelial dysplasia and normal oral mucosa. Head Neck Pathol 2012;6:305-13.

21. Etemad-Moghadam S, Khalili M, Tirgary F, Alaeddini M. Evaluation of myofibroblasts in oral epithelial dysplasia and squamous cell carcinoma. J Oral Pathol Med 2009;38:639-43.

22. Seifi S, Shafaei S, Shafigh E, Sahabi SM, Ghasemi H. Myofibroblast stromal presence and distribution in squamous epithelial carcinomas, oral dysplasia and hyperkeratosis. Asian Pac J Cancer Prev 2010;11:359-64.

23. Kellermann MG, Sobral LM, da Silva SD, Zecchin KG, Graner E, Lopes MA, et al. Mutual paracrine effects of oral squamous cell carcinoma cells and normal oral fibroblasts: Induction of fibroblast to myofibroblast transdifferentiation and modulation of tumor cell proliferation. Oral Oncol 2008;44:509-17.

24. Marsh D, Suchak K, Moutasim KA, Vallath S, Hopper C, Jerjes W, et al. Stromal features are predictive of disease mortality in oral cancer patients. J Pathol 2011;223:470-81.

25. Shimasaki N, Kuroda N, Miyazaki E, Hayashi Y, Toi M, Hiroi M, et al. The distribution pattern of myofibroblasts in the stroma of human bladder carcinoma depends on their invasiveness. Histol Histopathol 2006;21:349-53.

26. Chauhan H, Abraham A, Phillips JR, Pringle JH, Walker RA, Jones JL, et al. There is more than one kind of myofibroblast: Analysis of CD34 expression in benign, in situ, and invasive breast lesions. J Clin Pathol 2003;56:271-6.

27. Zhang Z, Tao D, Zhang P, Liu X, Zhang Y, Cheng J, et al. Hyaluronan synthase 2 expressed by cancer-associated fibroblasts promotes oral cancer invasion. J Exp Clin Cancer Res 2016;35:181.

28. Luksic I, Suton P, Manojlovic S, Virag M, Petrovecki M, Macan D, et al. Significance of myofibroblast appearance in squamous cell carcinoma of the oral cavity on the occurrence of occult regional metastases, distant metastases, and survival. Int J Oral Maxillofac Surg 2015;44:1075-80.

29. Cheng Y, Wang K, Ma W, Zhang X, Song Y, Wang J, et al. Cancer-associated fibroblasts are associated with poor prognosis in esophageal squamous cell carcinoma after surgery. Int J Clin Exp Med 2015;8:1896-903.

30. Hanley CJ, Mellone M, Ford K, Thirdborough SM, Mellows T, Frampton SJ, et al. Targeting the myofibroblastic cancer-associated fibroblast phenotype through inhibition of NOX4. J Natl Cancer Inst 2018;110:109-20. 